\title{
Lipografting - and Sculpturing in Female-to-Male Transgender Patients
}

\author{
Delia L Francia ${ }^{1 *}$, Maroesjka Spiekman², Martin C Harmsen ${ }^{2}$ and Motjaba Ghods ${ }^{1}$ \\ ${ }^{1}$ Department of Plastic and Reconstructive Microsurgery / Hand Surgery, Charité University Medicine Ernst Von Bergmann Clinic, Germany \\ ${ }^{2}$ Department of Pathology and Medical Biology, University of Groningen, The Netherlands
}

Submission: June 24, 2019; Published: July 17, 2019

*Corresponding author: Delia Letizia Francia, Consultant, Department of Plastic and Aesthetic Surgery, Reconstructive Microsurgery /Handsurgery, Charité University Medicine, Ernst von Bergmann Klinikum, Charlottenstraße 72, D-14467 Potsdam, Germany

\begin{abstract}
This case report presents several surgical procedures that amply lipotransfer and -sculpturing to treat specific volume sequelae and scarrelated impairments in FtM patients after failure of conservative surgical primary therapy. From November 2016 till November 2018 three FtM patients with typical scar related sequelae underwent sequential lipografting - and sculpturing. Our minimally invasive operative protocol (ACRT) was combined if required to a gender reassigning liposculpturing of the trunk or forearm augmentation for flap preformation. Clinical and aesthetic outcome were measured with photographs, the Patient and Observer Scar Assessment Scale (POSAS), Visual Analogue Scale (VAS) for pain, ROM measurements and nerve conduction studies (NCS). In all three patients a relevant functional and aesthetic improvement was achieved associated with very short hospitalization (average 3.2 days) and minor complications like swelling or bruising of the donor site. Clinical outcome showed improved scar appearance; $55 \%$ mean decrease of pain perception leading to $37 \%$ higher ROM in the left wrist mostly in extension. Increase of neophallus' size or forearm's subcutaneous layer prior to phalloplasty as well as a typical V-shape masculine trunk were accomplished after maximum three procedures.
\end{abstract}

Keywords: Liposculpturing; Fat grafting; Transgender surgery; Scar therapy

Abbrevations: FtM: Female to Male; ACRT: Adipose Cells Derived Regenerative Therapy; POSAS: Patient and Observer Scale; VAS: Visual Analogue Scale for pain; ROM; Range of Joint's Motion in Degrees; NCS: Nerve Conductive Studies /Measurement for Electrophysiological Functionality

\section{Introduction}

Lipografting is emerging as a treatment for postoperative sequelae, namely postoperative or posttraumatic contour and volume defects as well as dermal scars [1,2]. Liposuction may serve to remove excess volume, whereas lipografting of the harvested adipose tissue can be used to enhance and restore soft tissue volume defect [3-6]. Furthermore, lipografts remodel scar tissue by unknown mechanisms, which improves the elasticity and aesthetic aspect of the skin [7]. Another important feature of lipografting is pain reduction in neuropathic scars [8,9].

A group that could benefit from lipografting as a reconstructive treatment option for postoperative sequelae are patients suffering from gender identity disorder, that opt to undergo or underwent female-to-male (FtM) sex reassignment surgery. The term gender identity disorder is used for individuals, who experience a strong and persistent cross-gender identification and a persistent discomfort with their anatomical sex, as manifested by a preoccupation with getting rid of one's sex characteristics or the belief of being born with the wrong sex [10]. It is a relatively rare condition, with a prevalence roughly estimated from 1:30,040 to 1:104,000 in assigned females [11]. However, the prevalence of operative male-to-female transition is four times higher compared to female-to-male. Traditionally, the process of FtM transition is a staged. Initially, hormone therapy with testosterone is started to induce virilisation [12]. Then, the first stage of surgical sex reassignment is usually a subcutaneous mastectomy, which may be combined with hysterectomy and bilateral salpingo-oophorectomy. The second stage involves phalloplasty or metoidioplasty, combined with scrotoplasty and eventually with vaginectomy $[13,14]$. Although several techniques for phalloplasty e.g. anterior thigh flap, suprabubic flap, lattissimus dorsi flap are described the literature, the radial forearm flap phalloplasty is the most frequently performed [15]. After successful microsurgical transplantation a penile prosthesis, i.e. an inflatable erection device, and testicular prosthesis can be implanted [16]. 
The main functional and aesthetic aims of FtM sex reassignment surgery are micturition in standing position, visible bulk in under- or swimwear and preservation of genital sensation combined with the ability to achieve erection and penetration. These goals should be implemented in the therapeutic concept by surgeons, providing transmen an optimal fit in the desired gender role. However, sex reassignment surgery is linked to a high complication rate, while FtM patients also require numerous operative revisions to improve functional and aesthetic outcome [17]. Currently, no specific reconstructive treatment has evolved or particularly declared to improve the radial flap donor-site disfigurement, as well as functional impairment, i.e. in range of motion (ROM), due to the lacking subcutaneous adipose layer $[18,19]$. Furthermore, difficult-to-treat problems in FtM patients are painful and disfiguring scars on several body parts e.g. the pectoral or inguinal region. Genital skin irritation or pressure sores occur due to insufficient prosthesis coverage (i.e. penile or testicular implants) and frequent soft tissue volume defects (e.g. disproportionate scrotal or penile size) [20,21]. A remaining female aspect of the whole trunk including a wide hip region even after standardized mastectomy and hormone therapy may cause persistent discomfort and has not been described in a selective plastic surgical procedure yet [22]. Hence literature lacks standard operating protocols concerning sequelae after radial forearm flap phalloplasty or unsatisfactory results due to penile reconstruction [23-25].

This report describes results of specific designed operative concepts in order to approach the aforementioned problems as indications to revision systematically e.g. by using our minimal invasive scar release concept called Adipose Cells derived Regenerative Therapy (ACRT) in typical scar regions [26]. The pectoral contours were enhanced by lipografting and combined to liposculpturing of the lateral flanks and abdominal part for utter masculinization of the trunk. FtM patients in different stages of their gender affirmation process were included and

Table 1: Summary of the patients and lipografting procedures.

\begin{tabular}{|c|c|c|c|c|c|c|c|c|c|c|c|}
\hline \multirow{2}{*}{ Case } & \multirow{2}{*}{ Age } & \multirow{2}{*}{$\begin{array}{l}\text { Indications/Major } \\
\text { Complaints }\end{array}$} & \multirow{2}{*}{ Donor Side } & \multirow{2}{*}{ Recipient Side } & \multirow{2}{*}{ Complications } & \multicolumn{3}{|c|}{ OR- Time, Min } & \multicolumn{3}{|c|}{ Volume, cc } \\
\hline & & & & & & P1 & P2 & P3 & P1 & $\mathbf{P 2}$ & P3 \\
\hline 1 & 33 & $\begin{array}{l}\text { forearm scar con- } \\
\text { tracture, disfiguring } \\
\text { pectoral/trunk part }\end{array}$ & $\begin{array}{l}\text { abdomen, flanks, } \\
\text { hips, lateral thorax }\end{array}$ & $\begin{array}{c}\text { left forearm, pectoral } \\
\text { area }\end{array}$ & $\begin{array}{l}\text { haematoma, swell- } \\
\text { ing, synaesthesia }\end{array}$ & 120 & 130 & 106 & 80 & 123 & 178 \\
\hline 2 & 33 & $\begin{array}{l}\text { forearm scar } \\
\text { contracture, scrotal } \\
\text { prothesis, neophal- } \\
\text { lus size and shape }\end{array}$ & $\begin{array}{l}\text { abdomen, flanks, } \\
\text { hips }\end{array}$ & $\begin{array}{c}\text { left forearm, neo- } \\
\text { scrotum, neophallus, }\end{array}$ & haematoma, swelling & 102 & 126 & 126 & 84 & 89 & 135 \\
\hline 3 & 26 & $\begin{array}{l}\text { disfiguring pectoral/ } \\
\text { trunk part, pre-en- } \\
\text { hancement of radial } \\
\text { flap area }\end{array}$ & $\begin{array}{l}\text { abdomen, flanks, } \\
\text { hips }\end{array}$ & $\begin{array}{c}\text { left forearm, right } \\
\text { NAC, }\end{array}$ & swelling & 83 & 94 & 153 & 116 & 114 & 246 \\
\hline
\end{tabular}

OR-Time $=$ Operation - Time, $\min =$ minutes $; \mathrm{P}=$ Procedure .

All clinical outcomes were measured before and three months after operation through questionnaires (POSAS, VAS). In case of scar-related problems of the radial flap donor sites after

phalloplasty, the range of motion (ROM) of the wrist joint was assessed by means of goniometry and nerve conduction studies (NCS) were performed. In Patient 3 the forearm augmentation 
before phalloplasty was determined by measuring the thickness of the encharged subcutaneous layer via ultrasound imaging (GE P6 Premium, General Electronics Company, Illinois, U.S.A). Therefore, we used the US Probe ML 6-15 and performed double measurements with $12 \mathrm{MHz} / \mathrm{MI0} .9$ and $15 \mathrm{MHz} / \mathrm{MI} 0.5$.

\section{Surgical Techniques}

Patients presenting with either radial flap donor site scars or pectoral scars after mastectomy, were treated according to our standardized minimal invasive scar release procedure called the ACRT protocol [26]. In brief, the scar tissue of at the radial flap donor site or on other body parts was loosened by means of a minimal invasive scar release technique through maximum two stab incisions. Intra- and subdermal fibrotic tissue was undermined strictly horizontally to the skin level with specific sharp needles of different diameters (16 to 22 Gauge). Each scar area (15 to $80 \mathrm{~cm} 2$ ) had to be individually prepared for the grafting of lipoaspirates by following the projected spider web like design. The lipograft was harvested from the abdominal and hip region using the body-jet system with modified Klein's tumescence solution for waterjet assisted liposuction (human med AG, Schwerin) [27]. The liquid consists of isotonic saline solution supplemented with epinephrine (final dilution 0,0001\%, Infectopharm), Xylocaïn (0.049\%, Astrazeneca GmbH) and sodium bicarbonate (1.48\%, Fresenius Kabi Deutschland $\mathrm{GmbH}$ ). While waterjet assisted harvesting, the lipograft was contemporarily washed and filtered through the Lipocollector $\mathrm{III}^{\circ}$ - System (human med AG, Schwerin). Portions of $50 \mathrm{cc}$ were decanted and after $7 \mathrm{~min}$ transferred to $10 \mathrm{cc}$ Luer-Lock syringes. Fat was re-injected intra - and subdermally into the pre-treated scar area with a 7 to $12 \mathrm{~cm}$ long blunt tip cannula. Stab incisions were closed by temporary single sutures and dressing.

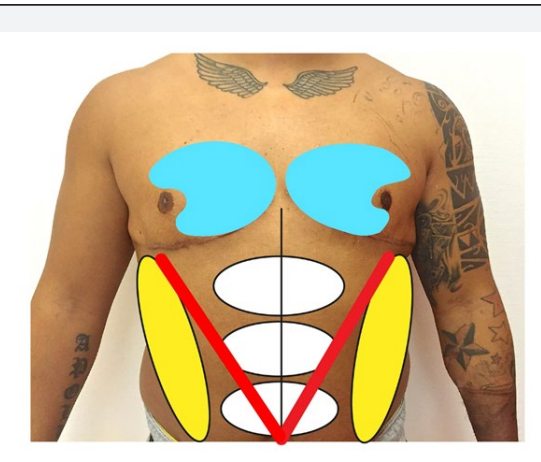

Figure 1: Trunk-Liposhape.

Fat grafting to the pectoral part (light blue) combined with specific liposuction of the lateral thoracic part, hips (yellow) and abdomen (white).

In order to gain a more masculine aspect of the chest wall and the abdominal part, we planned and marked the different areas of the trunk to address (Figure 1). By using a $3.8 \mathrm{~mm}$ sized multiple-hole cannula and water jet assisted liposuction the determined refinement of the hip and lateral thoracic part was performed in the first place. Preparation of the lipograft occurred with the Lipocollector III $^{\circ}$ - System and the adipose tissue was prepare in 10cc Luer -Lock syringes ready for reinjection. One stab incision was placed on each side in the lower margin of the NAC. Subdermal and intramuscular lipotransfer took place with 7 to $12 \mathrm{~cm}$ long blunt tip cannulas. In this way the inner and lower margins of the pectoral muscle were enhanced and underlined the masculine pectoral contours. Intraoperative the patients were sat in an upright position in order to control stepwise the symmetry and bilateral engraftment. The selective liposuction of excess fat on the abdomen, hips and flanks generally lead to the characteristic V-shape of a masculine trunk. Stab incisions were closed with single prolene sutures and covered with sterile dressings. The grafted area was cushioned with soft cotton bandings and a tight-fitting compression garment was put on in the operating room. Postoperatively, all patients received antibiotic treatment with cefuroxime $500 \mathrm{mg}$ per OS three times daily for a total of 5 days. A cushioned dressing was applied to the recipient site in order to avoid pressure on the lipograft for at least 10 days. In case of radial flap donor site augmentation, splinting was used for five days to avoid muscular tension or shear forces on the lipograft. Temporary sutures were removed after 5 to 7 days during routine control. Compression on the lipograft donor site was carried out for at least 4 weeks and muscular stress or sports were only allowed afterwards. Followup controls took place after one week, one and three months postoperatively.

\section{Results}

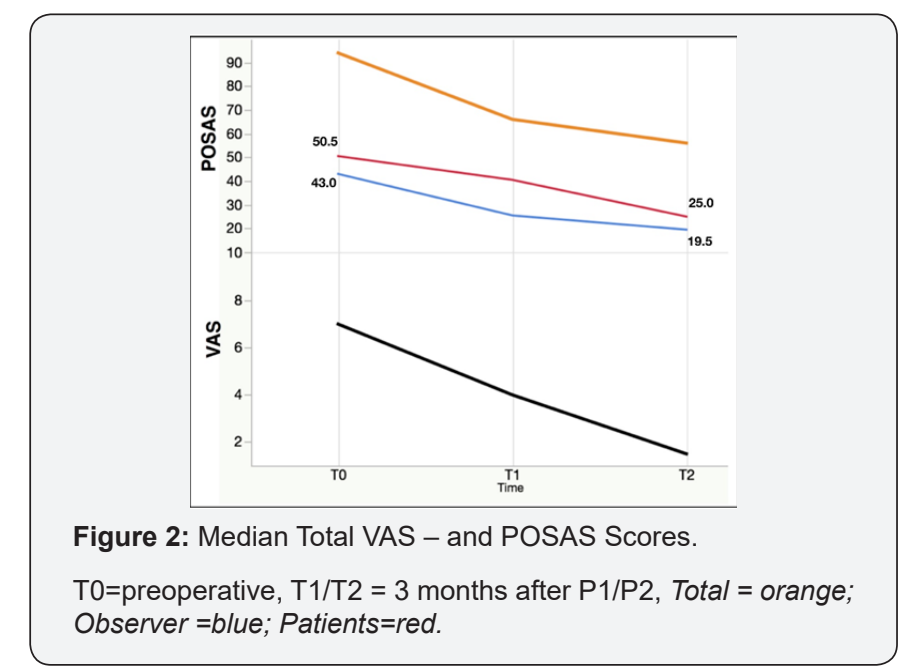

Almost all nine interventions contained at least two surgical techniques e.g. trunk liposhape combined with ACRT on several body parts with a median operation time of $120 \mathrm{~min}$ (range 83 to $153 \mathrm{~min}$ ). On average $129 \mathrm{cc}$ of lipograft (range 80 to $246 \mathrm{cc}$ ) was used per procedure with a total mean volume of $735 \mathrm{cc}$ per patient. For the trunk liposhape 160 to 200cc was needed and a total of $205 \mathrm{cc}$ was inserted for penile and scrotal correction. We recorded no major complications, but two minor complications in nine interventions due to our operative techniques. The first complication consisted of allodynia in the form of an 
electrical sensation and numbness in the first three fingers after lipografting in the radial flap donor site, indicating compression of the carpal tunnel. These symptoms were managed with conservative treatment and subsided spontaneously after five days. The second minor complication was haematoma formation after liposuction, which was treated conservatively and subsided after two weeks. Of note, none of the patients developed infection, donor-site irregularity, reactive scaring, oil cysts, fatty clumps or showed insufficient reuptake. Scars related issues and painful impairments were objectified by questionnaires (POSAS, VAS) preoperatively and 3 months after P1 and P2 (Figure 2). Benefit resulted by a notable reduction of the total scores for patients $(50.5 / 25.0)$ and for observers $(43.0 / 19.5)$ respectively. VAS also reduced, indicating a relief of pain due to the procedures applied. Preoperatively measured ROM and Tinel signs on the forearm improved mean $36.5 \%$ mostly in extension and radial abduction after the sequential subscar fat injection.

\section{Case Reports}

\section{Case 1}

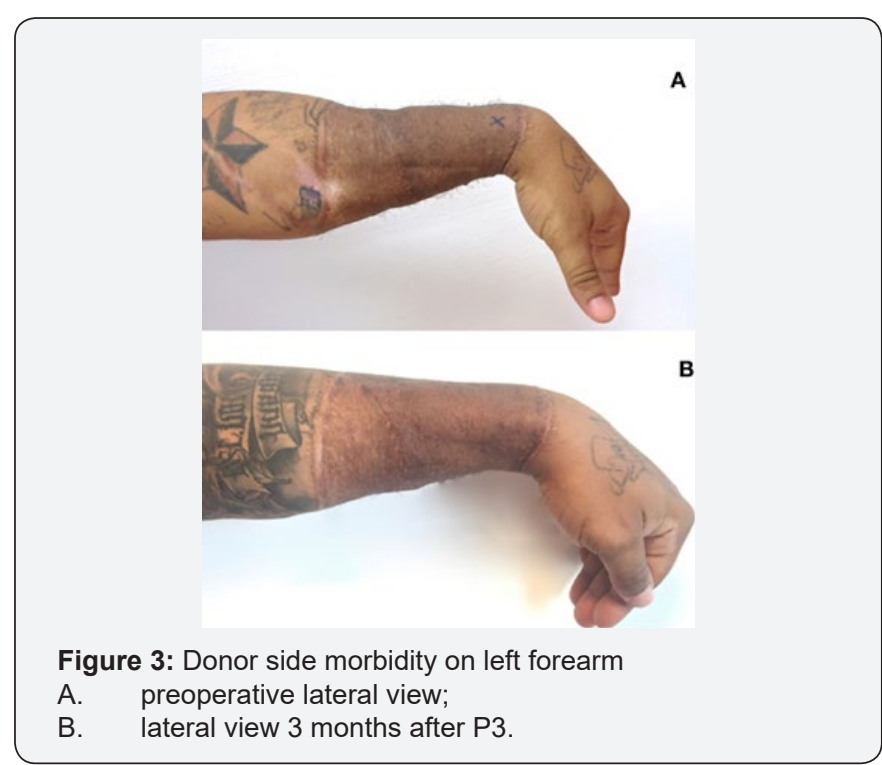

33 years old non-smoker with a BMI $28.4 \mathrm{~kg} / \mathrm{m} 2$, was enrolled in November 2015 for a painful scar adherence on the donor site two years after free radial forearm flap transplantation. He presented a skin type $\mathrm{V}$ according to Fitzpatrick with hypertrophic scarring and high pigmentation also on the pectoral area. Full skin graft originated from the inguinal area presented severe scar contraction on the left forearm and led to lessened movements such as $40^{\circ}$ extension, $10^{\circ}$ radial and $25^{\circ}$ ulnar abduction in the wrist. The patient complained about an obstructive sensation due to the reduced circumference on the proximal and distal edges of the scar area (Figure 3A). A Tinel sign was detected $1.7 \mathrm{~cm}$ distal and $3 \mathrm{~cm}$ proximally the superficial radial nerve area. Hypersensitivity led to a reduced quality life, e.g. the disability of wearing long arm clothes. Prior conservative treatment with silicone gels and sheets, compression garments and massages failed to alleviate patient's complaints. Besides overweight and conspicuous scar formation brought to an unpleasant aspect of the trunk and pectoral area (Figure 4A \& 4A). We performed three sessions of minimal invasive scar release method to the forearm and with $80 \mathrm{cc}, 123 \mathrm{cc}$ and $20 \mathrm{cc}$ of fat graft. After the first 3 months follow up the patient already gained $5^{\circ}$ to $10^{\circ}$ in the ROM of the wrist joint. Tinel sign was decreased detectable $1 \mathrm{~cm}$ distal and $1.6 \mathrm{~cm}$ proximally the radial nerve area, indicating a local cushioning or embedding effect of the inserted lipograft. After the next intervention functional impairments like neuropathic pain diminished even more. This was confirmed by reduced VAS scores from preoperatively 6 (nearly acceptable pain) to final 1 (almost none). Finally, the initial tethering scar aspect in texture regained high pliability and ROM in the donor wrist improved to painless completion (Figure 3B). By using the aforementioned trunk liposhape approach, we removed 390cc pure fat and transplanted $160 \mathrm{cc}$ graft volume in the predefined parts. In this way we obtained a dominant masculine aspect of the pectoral contours combined with a flattening definition of the lateral thoracic part, flanks, abdomen and hips (Figure 4C \& 4D).

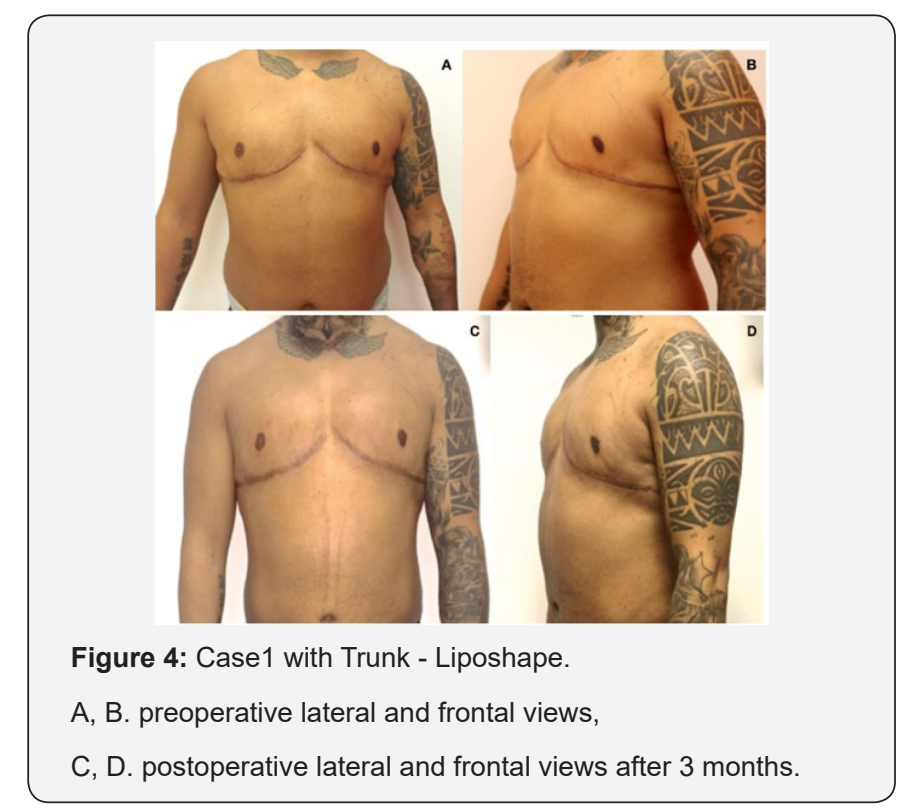

\section{Case 2}

33 years old non-smoker with a BMI $20.5 \mathrm{~kg} / \mathrm{m} 2$, showed in January 2016 painful and hypersensitive scar formation after free radial forearm phalloplasty with full split skin graft to the donor site in October 2012. ROM was reduced with $25^{\circ}$ extension, $10^{\circ}$ radial and $15^{\circ}$ ulnar abduction. In addition, recurrent wounds and skin lesions occurred due to poor skin coverage of the penile pump system and right scrotal prosthesis. We noticed a peculiar shape of scrotal part and the neophallus after completed scar maturation and partial shrinking of the flap's soft tissue (Figure $5 \mathrm{~A}-5 \mathrm{C}$ ). Before surgery the conservative treatment of the forearm consisted in massages, silicone gel, compression and steroid injection. Preoperative measurements detect a Tinel sign $4 \mathrm{~cm}$ proximally and $2.5 \mathrm{~cm}$ distal of the radial innervated field. Nerve 
conduction revealed a reduced velocity and amplitude of the left affected superficial branch in comparison to the opposite side (left $17.9 \mathrm{mV} ; 59.9 \mathrm{~m} / \mathrm{s}$ vs right $86.3 \mathrm{mV} ; 65.7 \mathrm{~m} / \mathrm{s}$ ). Sonographic measurements of the skin layer determined a thickness of $0.9 \mathrm{~mm}$ over the main branch.

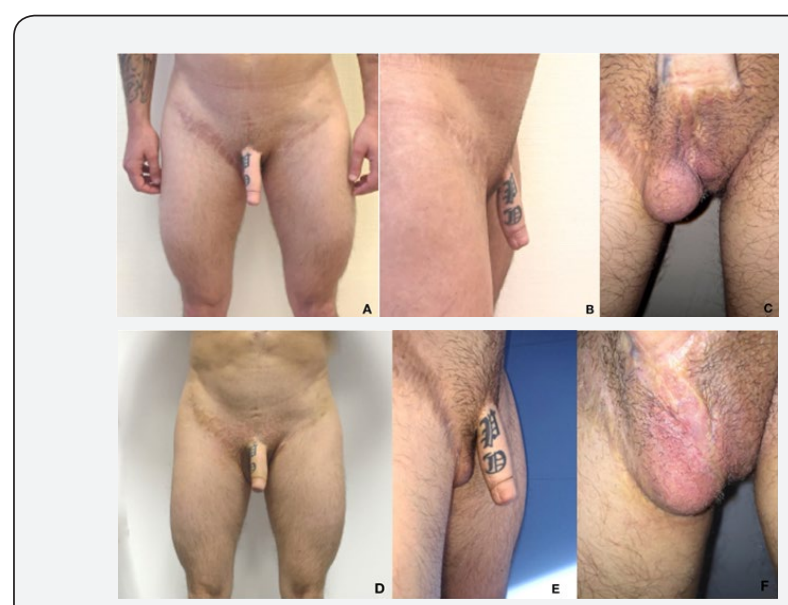

Figure 5: Case1 with Trunk - Liposhape.

A, B. preoperative lateral and frontal views,

C, D. postoperative lateral and frontal views after 3 months.

Patient's expectations on our operative therapy addressed alleviation of the obstructive sensation as well as neuropathic symptoms caused by the rigid circumferential scar area on the donor side, conspicuous aspect of the of the neophallus and left neoscrotum plus ventralisation of the right scrotal prosthesis. After the first operation the Tinel sign was reduced detectable $3.2 \mathrm{~cm}$ distal and 1.4 proximally from the radial branch and ROM of the wrist improved especially $10^{\circ}$ ulnar and radial abduction. The nerve conduction demonstrated a lowering of the amplitude after each fat grafting session, although the velocity persisted low (left $8.3 \mathrm{mV} ; 59.9 \mathrm{~m} / \mathrm{s}$ vs right $85.7 \mathrm{mV} ; 65.9 \mathrm{~m} / \mathrm{s}$ ). Thickening of the local skin layer was estimated of $1.3 \mathrm{~mm}$ by ultrasound. In the second session ACRT-concept on the forearm and penile area was done in combination to ventralisation of the right scrotal prosthesis and lipografting to the neophallus. Stepwise a soften coverage of the penile pump system in the left neoscrotum and widening of the penile circumferential scar have been achieved (Figure 5D-5F). In By loosening the fibrotic entrapment and thickening the subcutaneous layer on the donor side neuropathic symptoms decreased according to a Tinel sign $1.2 \mathrm{~cm}$ proximally and $1.3 \mathrm{~cm}$ distal. ROM rapidly improved and reached except $5^{\circ}$ in supination painless completion. Questionnaires evaluation estimated a decrease of the Patients baseline POSAS score from preoperatively 88 to 48 as well as VAS scores from 8 (severe pain) to 2 (mild pain). However, he showed no recurrence of erythema, inflammation or wounds in the genital region during the complete follow up. Hence penile diameter increased $0.9 \mathrm{~cm}$ and stayed stable in shape without problems in urologic or erectile function providing more self-confidence in patient's sexuality.

\section{Case 3}

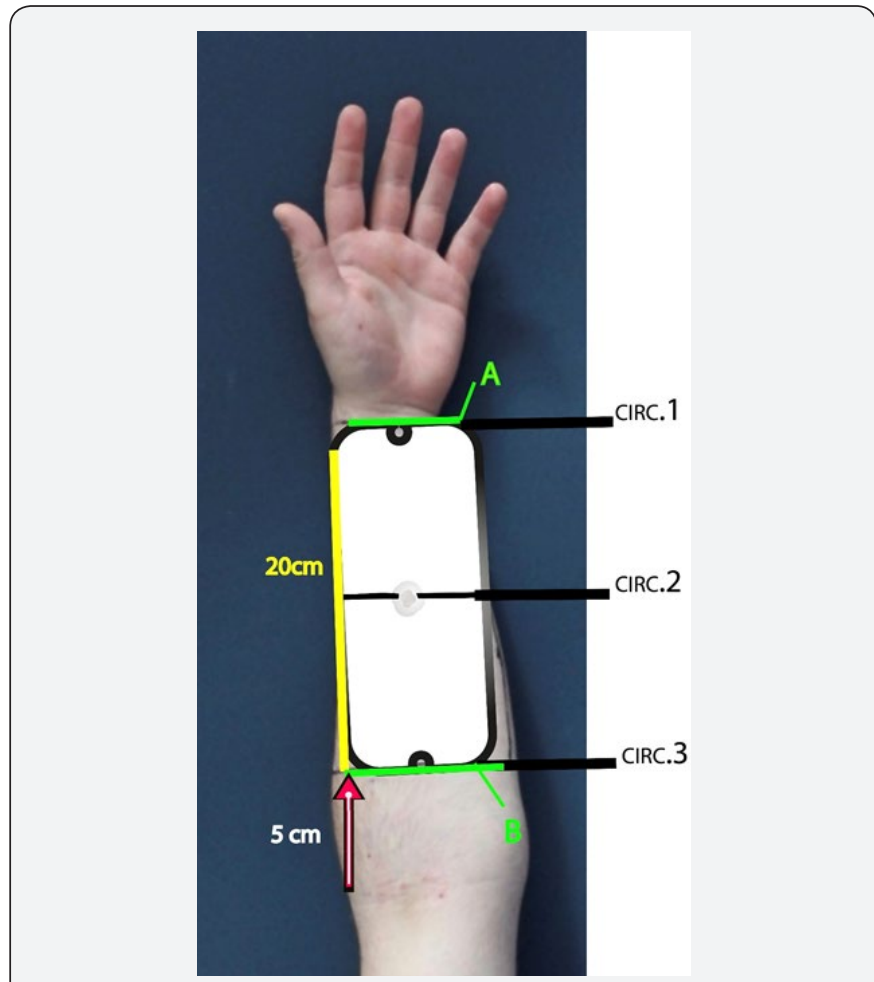

Figure 6: Prefabrication donor side's design before phalloplasty (white).

Fixed length with $20 \mathrm{~cm}$ placed $5 \mathrm{~cm}$ from the cubital fold.

Proximal (B) and distal (A) widths increase by lipografting as well as forearm's circumference (CIRC 1-3).

Subcutaneous layer detected by ultrasound (grey spots).

26 years old, smoker (10py) with a BMI of $28.2 \mathrm{~kg} / \mathrm{m} 2$ was planned for mastectomy as the first intervention after one year of hormone therapy. Since FtM patients' complaints had been reported about postoperative soft tissue shrinking and decreased penile size after radial free flap phalloplasty, we conducted a pre-enhancement before flap harvest through sequential lipografting. The design of the future donor side was marked on the nondominant left medial forearm (Figure 6). We chose larger outlines, i.e. $20 \mathrm{~cm}$ length in order to correspond an enhanced shape of the "prefabricated" flap after microsurgical transplantation. Preoperative clinical measurements recorded forearm's circumferences, sonography assessed the thickness of the subcutaneous layer and controlled the vascularity during the prefabrication process on several levels: wrist (CIRC1), half middle forearm (CIRC2) and proximal forearm (CIRC3). In the first procedure the mastectomy and waterjet assisted lipografting of $116 \mathrm{cc}$ from the abdomen to the left arm took place. Afterwards hypertrophic scarring and an unpleasant aspect of the right NAC due to partial necrosis and wound healing problems were noticed (Figure 7A). In the second procedure we applied the scar release method to treat the right fibrotic deformed NAC and pectoral scar $(23 \mathrm{cc})$ simultaneously with the forearm augmentation 
through 94cc autologous fat graft harvested from both flanks. In this way we obtained symmetry in the pectoral part and a thickening of the subcutaneous layer of the left forearm. In order to provide a reliable soft tissue enhancement of the future donor side and a masculine aspect of the chest, the patient underwent a third forearm augmentation (96cc) combined to the trunk liposhape approach (Figure 7B). Here we removed $480 \mathrm{cc}$ fat from the abdomen, flanks and lateral thoracic area and transplanted $100 \mathrm{cc}$ subcutaneously and $70 \mathrm{cc}$ intramuscularly to enhance the pectoral muscle contour. Postoperatively forearm's circumferences showed a mean increase of $2,6 \mathrm{~cm}$ (ranged $0,8 \mathrm{~cm}$ to $5,6 \mathrm{~cm}$ ) (Table 2). Furthermore, ultrasound measurements proved intact vascularity by Doppler and a successful engraftment in the "prefabricated" flap area (Figure 8A \& 8B). In summary patient maintained excellent functional and aesthetic aspect of the forearm after insertion of 303cc lipograft with the technique described.

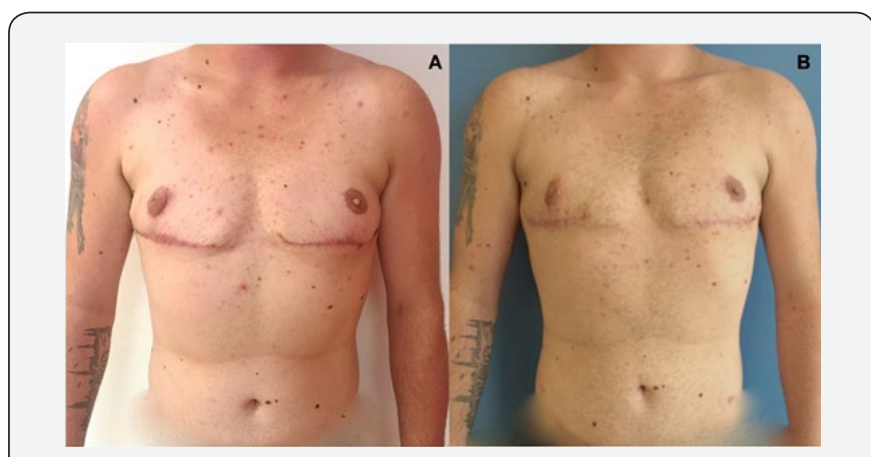

Figure 7: Case 3 with Trunk - Liposhape.

A. 3 months after mastectomy;

B. frontal view of the trunk 3 months after $\mathrm{P} 3$.

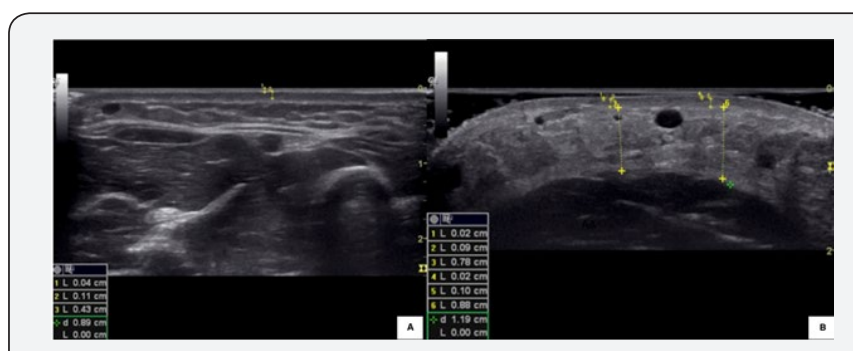

Figure 8: Enhancement of the subcutaneous tissue measured by ultrasound.

A. preoperative thickness $(0,43 \mathrm{~cm})$;

B. 3 months after P3 $(0,88 \mathrm{~cm})$.

Table 2: Soft tissue increase with lipograft before radial flap based phalloplasty (cm).

\begin{tabular}{|c|c|c|c|c|c|}
\hline & A & B & CIRC1 & CIRC2 & CIRC3 \\
\hline T0 & 7,5 & 12 & 17 & 19 & 26,5 \\
\hline T1 & 7,5 & 12,5 & 17,7 & 23 & 28 \\
\hline T2 & 8,7 & 12,9 & 18,4 & 24,8 & 27,7 \\
\hline T3 & 8,5 & 12,8 & 18,1 & 24,6 & 28,3 \\
\hline Mean Total Increase (\%) & 11,76 & 6,67 & 6,47 & 29,47 & 6,79 \\
\hline
\end{tabular}

$\mathrm{T} 0=$ preoperative $; \mathrm{Tx}=3$ months postoperative .

\section{Discussion}

The most important goal of female-to-male genital reassignment surgery is an inartificial masculine outer aspect accompanied with optimal penile reconstruction, which allows the FtM patients to void standing up and sexually interact with penetration $[13,28]$. Even though multiple operative steps are taken during the process, remarkable paucity exists concerning specific techniques to address persistent scar related disfigurements, donor side disability with neuropathic pain, trunk contour deformities after mastectomy, dislocation of scrotal implants or tissue expansion in the mean of secondary surgical corrections $[29,30]$. Our lipografting protocol combined with a minimal invasive scar release called ACRT was performed in the abovementioned three FtM transgender cases to improve the scar related complaints on the donor forearm after free radial forearm flap like rigid adherence, pain sensation in the superficial radial nerve area, decreased ROM, differing pigmentation, shrinking of the subcutaneous fatty layer. Upgraded appearance in scar area as well as a pliant skin texture measured by POSAS scale system, probably lead to complete painless ROM of the donor wrist. Obvious reduction of the neuropathic features registered through VAS Scores, Tinel sign's exhibition, nerve conduction and ultrasound measurements, seemed to be linked to fat graft's cushioning (mechanical) and regenerative effect recently described in scars in addition to minimal invasive release of fibrotic tension on the nerve $[8,9,31]$. Conversely literature reports, that scarring in the forearm's skin graft do mainly result in functional and pain-free donor side with high patient satisfaction $[10,17,18]$. We feel, that the ACRTprotocol offers a powerful tool for systematic fibrotic loosening of the scar area without compromising the vascularity of the full skin graft in patients with persistent donor side's complaints.

Furthermore, this technique was applied to treat aberrant scars due to conservative sex-reassignment mastectomy and radial flap based phalloplasty. In the pectoral area we corrected hypertrophic post-mastectomy scars and regained projection of the nipple. In the genital part we obtained a distension of the inguinal and circumferential penile scars, simultaneous lipografting lead to an enhanced and pendulous shape to the neophallus. Autologous fat transplantation with or without transcutaneous needling of fibrotic tissue has been generally described and proclaimed as promising treatment before [32-34]. Even though systematic transcutaneous needling accompanied by lipografting as synergistic methods in symptomatic scars have not been elucidated in detail or even established as a standard operating procedure(s) (SOP) yet $[35,36]$. Latter has been established as the ACRT-protocol in our institution for FtM patients with promising results so far. Although controlled randomized studies including a large number cohort are required to verify its evidence.

Scrotoplasty is usually performed with the insertion of silicone implants using the labia majora with or without prior 
tissue expansion or simultaneous advancement of local skin flaps [37]. Postoperative dislocation of the scrotal implants may provoke skin affections and a hidden aspect of the neoscrotum especially in the lateral view. Poor skin coverage with implant expulsion, mechanical dysfunction or dislocation are known as typical complications after insertion of a hydraulic balanced penile prosthesis [38,39]. To overcome these drawbacks even more surgical interventions and downtime periods are required. In case 2 ventralisation of the right neoscrotum and a cushioning soft tissue coverage over the penile pump system succeeded within short and easy to perform sessions. Follow-ups were uneventful and avert further conservative amendments. The use of lipografing to enhance the subcutaneous skin layer is widely performed in breast surgery e.g. to camouflage the outlines of breast implants [40-42]. However up to date there is no literature reporting the use of autologous fat transplantation for scrotal sequelae in FtM patients.

Ultimately lipografting offered directed soft tissue augmentation for the use of radial free flap prefabrication before phallic construction without notable complications in patient 3. Before different approaches were proposed to derate secondary corrections, functional and aesthetic impairments after phalloplasty e.g. specific closures of the donor side, prelamination with a tube for urethroplasty, or pre-extension by tissue expansion [43-45]. Most techniques include an additional surgical team during time- consuming interventions, notable major complications and prolonged immobilization or demand high patient's compliance $[46,47]$. On the other hand, the presented concept of radial free flap prefabrication is surgically feasible as an ambulatory treatment and the forearm's fatty layer might almost be doubled within three procedures in patients heading to forearm's flap based phalloplasty. However, the operative approach is presented as a single case so far and must be investigated in a larger cohort including a longer follow up. Finally, pectoral lipografting combined to distinctive liposuction on different parts of the trunk was designed as Trunk Liposhape and led to improved upper masculinization. Our study has limitations such as a low patient number, short follow-up period, observer bias, but this pilot approach provided a first and preliminary impression about reconstructive techniques that have not been described for that patient group so far. Besides, all patients stated that they would undergo the same procedures considering the complications and postoperative results.

\section{Conclusion}

Lipografting - if a proper patient selection and operative procedures are applied - is a minimally invasive and patient friendly solution for aesthetic improvement of sequelae resulting from female-to-male sex reassignment surgery. Both symptoms and aesthetic issues create in this specific patient group a large burden in daily and professional life with a permanent reduction of the quality of life or psychological distress. Up to date therapeutic and surgical approaches are limited, that's why the new concepts had been developed and applied as "rescue" procedures in our department with an acceptable safety profile.

The standard minimal invasive scar release protocol of ACRT combined with or without the Transgender-Trunk Liposhape (TTL) could be used in cases when all previous attempts of conservative treatment have failed. Further clinical studies with large numbered patient groups and recording of a long-term effectiveness are highly recommended and certainly necessary.

\section{Acknowledgements}

Michael Scheit M.D., Department of Anaesthesiology Ernst von Bergmann Clinic for ultrasound measuring.

\section{Compliance with Ethical Standards}

\section{Funding}

The work was funded by the University Medical Centre Groningen, University of Groningen, the Netherlands and was supported by grants from the Jan-Kornelis de Cock Foundation (to Author B), Ubbo Emmius Fund - Junior Scientific Masterclass Talent Grant (to Author B) and Foundation "De Drie Lichten" (to Author B), the Netherlands. Furthermore, this study was financially supported by human med AG, Germany by grants (to Author A) and by contribution of supplies for the Body-Jet Waterjet Assisted Liposuction System. The funders had no role in study design, data collection and analysis or manuscript preparation.

\section{Conflict of interest}

Author A and B received research grants and traveling costs for study meetings and speaking at symposia from human med AG, Schwerin - Germany. Author C and Author D declare that they have no conflict of interest.

\section{Ethical approval}

The treatments described have been approved by the medical Ethical committee the local clinical institution (reference number 167/2015MPG43). All procedures performed in studies involving human participants were in accordance with the ethical standards of the institutional research committee and with the 1964 Helsinki declaration and its later amendments or comparable ethical standards.

\section{Informed consent}

Informed consent was obtained from all individual participants included in the study.

Additional informed consent was obtained from all individual participants for whom identifying information is included in this article.

\section{References}

1. Khouri RK, Smit JM, Cardoso E, Pallua N, Lantieri L, et al. (2013) Percutaneous aponeurotomy and lipofilling: a regenerative alternative to flap reconstruction? Plast Reconstr Surg 132(5): 1280-1290. 
2. Klinger M, Caviggioli F, Klinger FM, Giannasi S, Bandi V, et al. (2013) Autologous fat graft in scar treatment. J Craniofac Surg 24(5): 16101615.

3. Delay E, Garson S, Tousson G, Sinna R (2009) Fat injection to the breast: technique, results, and indications based on 880 procedures over 10 years. Aesthet Surg J 29(5): 360-376.

4. Kang DH, Chung JH, Kim YJ, Lee HN, Cho SH, et al. (2012) Efficacy and safety of penile girth enhancement by autologous fat injection for patients with thin penises. Aesthetic Plast Surg 36(4): 813-818.

5. Agostini T (2014) Fat transfer in 2014: what we do not know. Plast Reconstr Surg 134(6): 992e-993e.

6. Coleman SR, Saboeiro AP (2015) Primary Breast Augmentation with Fat Grafting. Clin Plast Surg 42(3): 301-306.

7. Spiekman M, van Dongen JA, Willemsen JC, Hoppe DL, van der Lei B, et al. (2017) The power of fat and its adipose-derived stromal cells: emerging concepts for fibrotic scar treatment. J Tissue Eng Regen Med 11(11): 3220-3235.

8. Huang SH, Wu SH, Chang KP, Lin CH, Chang CH, et al. (2015) Alleviation of neuropathic scar pain using autologous fat grafting. Ann Plast Surg 74 Suppl 2: S99-S104.

9. Fredman R, Edkins RE, Hultman CS (2016) Fat Grafting for Neuropathic Pain After Severe Burns. Ann Plast Surg 76 Suppl 4: S298-S303.

10. Selvaggi G, Ceulemans P, De Cuypere G, VanLanduyt K, Blondeel P, et al. (2005) Gender identity disorder: general overview and surgical treatment for vaginoplasty in male-to-female transsexuals. Plast Reconstr Surg 116(6): 135e-145e.

11. Collin L, Reisner SL, Tangpricha V, Goodman M (2016) Prevalence of Transgender Depends on the "Case" Definition: A Systematic Review. J Sex Med 13(4): 613-626.

12. Gooren LJ (2014) Management of female-to-male transgender persons: medical and surgical management, life expectancy. Curr Opin Endocrinol Diabetes Obes 21(3): 233-238.

13. Frey JD, Poudrier G, Chiodo MV, Hazen A (2017) An Update on Genital Reconstruction Options for the Female-to-Male Transgender Patient: A Review of the Literature. Plast Reconstr Surg 139(3): 728-737.

14. Wolter A, Diedrichson J, Scholz T, Arens-Landwehr A, Liebau J (2015) Sexual reassignment surgery in female-to-male transsexuals: an algorithm for subcutaneous mastectomy. J Plast Reconstr Aesthet Surg 68(2): 184-191

15. Colebunders B, Brondeel S, D’Arpa S, Hoebeke P, Monstrey S (2017) An Update on the Surgical Treatment for Transgender Patients. Sex Med Rev 5(1): 103-109.

16. Selvaggi G, Monstrey S, Hoebeke P, Ceulemans P, Van Landuyt K, et al (2006) Donor-site morbidity of the radial forearm free flap after 125 phalloplasties in gender identity disorder. Plast Reconstr Surg 118(5) 1171-1177.

17. Van Caenegem E, Verhaeghe E, Taes Y, Wierckx K, Toye K, et al. (2013) Long-term evaluation of donor-site morbidity after radial forearm flap phalloplasty for transsexual men. J Sex Med 10(6): 1644-1651.

18. Ito O, Igawa HH, Suzuki S, Muneuchi G, Kawazoe T, et al. (2005) Evaluation of the donor site in patients who underwent reconstruction with a free radial forearm flap. J Reconstr Microsurg 21(2): 113-117.

19. de Witt CA, de Bree R, Verdonck-de Leeuw IM, Quak JJ, Leemans CR (2007) Donor site morbidity of the fasciocutaneous radial forearm flap: what does the patient really bother? Eur Arch Otorhinolaryngol 264(8): 929-934.

20. Rieger UM, Majenka P, Wirthmann A, Sohn M, Bozkurt A, et al. (2016) Comparative Study of the Free Microvascular Groin Flap: Optimizing the Donor Site After Free Radial Forearm Flap Phalloplasty. Urology 95: 192-196.

21. Selvaggi G, Dhejne C, Landen M, Elander A (2012) The 2011 WPATH Standards of Care and Penile Reconstruction in Female-to-Male Transsexual Individuals. Adv Urol 2012: 581712

22. Lo Russo G, Tanini S, Innocenti M (2017) Masculine Chest-Wall Contouring in FtM Transgender: a Personal Approach. Aesthetic Plast Surg 41(2): 369-374.

23. Byun SH, Ahn KM, Kim SM, Lee JH (2016) Functional and cosmetic outcome after closure of radial forearm free flap donor defect with porcine collagen membrane. J Craniomaxillofac Surg 44(5): 527-532.

24. Schmidt M, Grohmann M, Huemer GM (2015) Pedicled superficial inferior epigastric artery perforator flap for salvage of failed metoidioplasty in female-to-male transsexuals. Microsurgery 35(5): 403-406.

25. Doornaert M, Hoebeke P, Ceulemans P, T'Sjoen G, Heylens G, et al. (2011) Penile reconstruction with the radial forearm flap: an update. Handchir Mikrochir Plast Chir, 43(4): 208-214.

26. Hoppe DL (2016) Volumendefekte an Stamm und Extremitäten. In Ueberreiter K (Ed.), Autologe Fettgewebstransplantation, SpringerVerlag Berlin Heidelberg: Germany.

27. Ueberreiter K, von Finckenstein JG, Cromme F, Herold C, Tanzella U, et al. (2010) [BEAULI ${ }^{\mathrm{T}}$--a new and easy method for large-volume fat grafts]. Handchir Mikrochir Plast Chir 42(6): 379-385

28. Berli JU, Knudson G, Fraser L, Tangpricha V, Ettner R, et al. (2017) What Surgeons Need to Know About Gender Confirmation Surgery When Providing Care for Transgender Individuals: A Review. JAMA Surg 152(4): 394-400.

29. Sutcliffe PA, Dixon S, Akehurst RL, Wilkinson A, Shippam A, et al. (2009) Evaluation of surgical procedures for sex reassignment: a systematic review. J Plast Reconstr Aesthet Surg 62(3): 294-306.

30. Monstrey S, Hoebeke P, Selvaggi G, Ceulemans P, Van Landuyt K, et al. (2009) Penile reconstruction: is the radial forearm flap really the standard technique? Plast Reconstr Surg 124(2): 510-518.

31. Huang SH, Wu SH, Chang KP, Cheng KI, Lee SS, et al. (2014) Autologous fat grafting alleviates burn-induced neuropathic pain in rats. Plast Reconstr Surg 133(6): 1396-1405.

32. Baptista C, Iniesta A, Nguyen P, Legré R, Gay AM (2013) Autologous fat grafting in the surgical management of painful scar: preliminary results. Chir Main 32(5): 329-334.

33. Bollero D, Pozza S, Gangemi EN, De Marchi A, Ganem J, et al. (2014) Contrast-enhanced ultrasonography evaluation after autologous fat grafting in scar revision. G Chir 35(11-12): 266-273.

34. Klinger M, Marazzi M, Vigo D, Torre M (2008) Fat injection for cases of severe burn outcomes: a new perspective of scar remodeling and reduction. Aesthetic Plast Surg 32(3): 465-469.

35. Jaspers MEH, Brouwer KM, van Trier AJM, Middelkoop E, van Zuijlen PPM (2017) Sustainable effectiveness of single-treatment autologous fat grafting in adherent scars. Wound Repair Regen 25(2): 316-319.

36. Zeitter S, Sikora Z, Jahn S, Stahl F, Strauß S, et al. (2014) Microneedling: matching the results of medical needling and repetitive treatments to maximize potential for skin regeneration. Burns 40(5): 966-973.

37. Perovic SV, Djordjevic ML (2003) Metoidioplasty: a variant of phalloplasty in female transsexuals. BJU Int 92(9): 981-985.

38. Hoebeke PB, Decaestecker K, Beysens M, Opdenakker Y, Lumen N et al. (2010) Erectile implants in female-to-male transsexuals: our experience in 129 patients. Eur Urol 57(2): 334-340. 
39. Garcia MM, Christopher NA, De Luca F, Spilotros M, Ralph DJ (2014) Overall satisfaction, sexual function, and the durability of neophallus dimensions following staged female to male genital gender confirming surgery: the Institute of Urology, London U.K. experience. Transl Androl Urol 3(2): 156-162.

40. Moltó García R, González Alonso V, Villaverde Doménech ME (2014) Fat grafting in immediate breast reconstruction. Avoiding breast sequelae. Breast Cancer 23(1): 134-140.

41. Ho Quoc C, Michel G, Dlimi C, Gourari A, Meruta A, et al. (2014) Percutaneous fasciotomies to improve fat grafting into the breast. Ann Chir Plast Esthet 59(2): 130-135.

42. Roça GB, Graf R, da Silva Freitas R, Salles G, Francisco JC, et al. (2014) Autologous Fat Grafting for Treatment of Breast Implant Capsular Contracture: A Study in Pigs. Aesthet Surg J 34(5): 769-775.

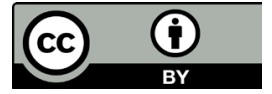

This work is licensed under Creative Commons Attribution 4.0 License DOI: $10.19080 / J O J C S .2019 .10 .555788$
43. Küntscher MV, Hartmann B (2011) The radial forearm phalloplasty with prelaminated urethra: a report of our learning curve during the last 6 years. Handchir Mikrochir Plast Chir 43(4): 222-226.

44. Scholten MM, Grundentaler R, Bull S, Küntscher MV (2013) Variety of the radial forearm phalloplasty with respect to urethral construction a review. Handchir Mikrochir Plast Chir 45(4): 211-216.

45. Wester JL, Pittman AL, Lindau RH, Wax MK (2014) AlloDerm with splitthickness skin graft for coverage of the forearm free flap donor site. Otolaryngol Head Neck Surg 150(1): 47-52.

46. Selvaggi G, Branemark R, Elander A, Liden M, Stalfors J (2015) Titanium-bone-anchored penile epithesis: preoperative planning and immediate postoperative results. J Plast Surg Hand Surg 49(1): 40-44

47. Selvaggi G, Elander A, Branemark R (2010) Penile epithesis: preliminary study. Plast Reconstr Surg 126(5): 265e-266e.

\section{Your next submission with Juniper Publishers will reach you the below assets}

- Quality Editorial service

- Swift Peer Review

- Reprints availability

- E-prints Service

- Manuscript Podcast for convenient understanding

- Global attainment for your research

- Manuscript accessibility in different formats

( Pdf, E-pub, Full Text, Audio)

- Unceasing customer service

Track the below URL for one-step submission https://juniperpublishers.com/online-submission.php 